\title{
CASIM and Ground Water Activation \\ Calculations at the A0 Abort
}

\author{
C.Y. Tan \\ Beams Division \\ Fermilab
}

\begin{abstract}
The results of CASIM and ground water activation calculations for the A0 abort is presented in this paper. CASIM calculations were done at $150 \mathrm{GeV}$ and $1 \mathrm{TeV}$ for the following transverse beam sizes $\left(\sigma_{x}, \sigma_{y}\right):(0.15 \times$ $0.15) \mathrm{mm}^{2},(0.15 \times 0.15) \mathrm{cm}^{2}$, and $(1.5 \times 1.5) \mathrm{cm}^{2}$. The results from CASIM were used to calculate the ground water activation using the Concentration Model. The results show that there is only a weak dependance on the transverse beam size and that the maximum number of protons which can be aborted at A0 per year is $7.6 \times 10^{16}$ protons/year @150 GeV and $1.7 \times 10^{16}$ protons/year @1 TeV
\end{abstract}




\section{INTRODUCTION}

In this paper, we will calculate the maximum number of protons per year that can be dumped into the A0 abort. The hard limit of this number is bounded by the requirement that the ground water contamination from both tritium $\left(\mathrm{H}_{3}\right)$ and sodium $\left(\mathrm{Na}_{22}\right)$ stay under the EPA and DOE limits. The models used in our calculations are based on CASIM and the Concentration Model.

CASIM is a Monte Carlo programme used to calculate the the number of nuclear interactions (called stars in CASIM) in the A0 geometry from which the region of maximum star density in the soil can be identified. The region thus identified is used in the Concentration Model to calculate the concentration of $\mathrm{H}_{3}$ and $\mathrm{Na}_{22}$ after their migration from the production source to the ground water. With the legal environmental limits as upper bounds, we will calculate the maximum number of protons that can be aborted in A0 for two different incident energies: $150 \mathrm{GeV}$ and $1 \mathrm{TeV}$ with three different transverse beam sizes: $\left(\sigma_{x}, \sigma_{y}\right):(0.15 \times 0.15) \mathrm{mm}^{2},(0.15 \times 0.15) \mathrm{cm}^{2}$, and $(1.5 \times 1.5) \mathrm{cm}^{2}$. 


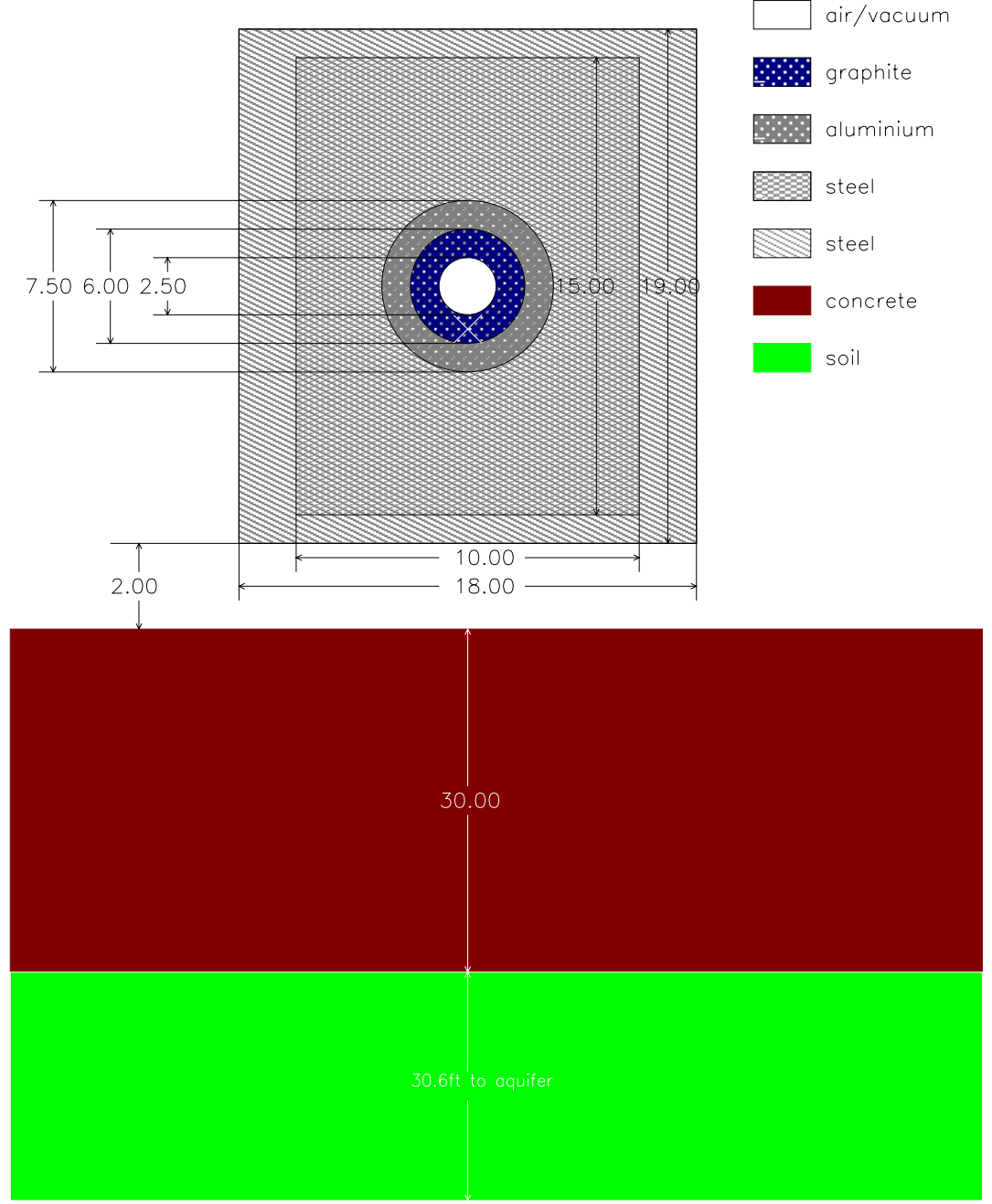

Figure 1 This is the transverse view of the geometry used in CASIM. The dimensions are in inches unless explicitly noted. Note: The dimensions are correct but the drawing scale has been modified for clarity.

\section{CASIM CALCULATIONS}

The CASIM calculations were performed with the geometry shown in Figures 1 and 2. These figures were based on assembly drawings ${ }^{1}$ while the thickness of the concrete floor of 30 " came from Hanna ${ }^{2}$. The distance to the aquifer came from Malensek ${ }^{3}$ who 


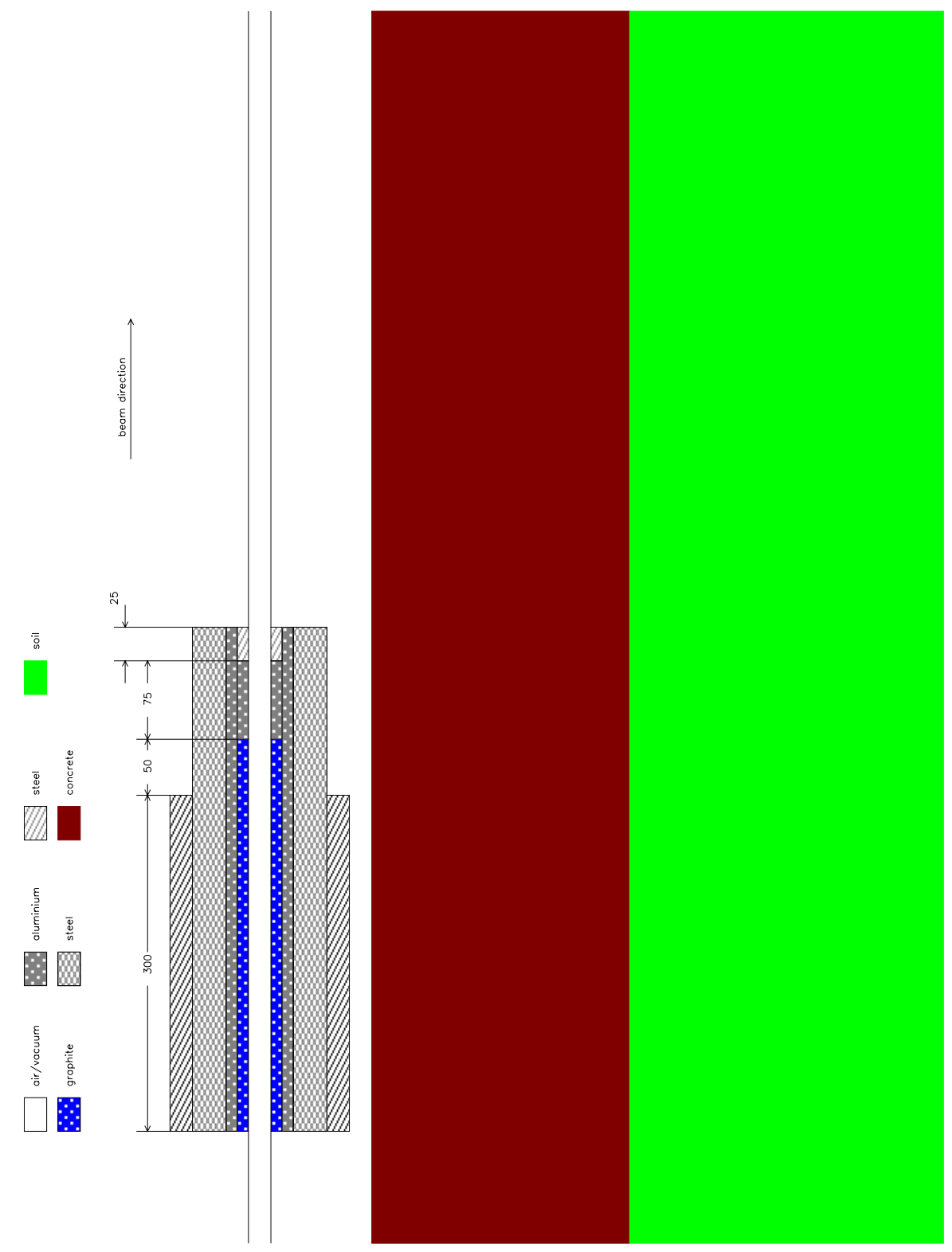

Figure 2 This is the longitudinal view of the geometry used in CASIM. The dimensions are in $\mathrm{cm}$.

gave the adjusted distance to the aquifer as $11.6 \mathrm{~m}$ while according to Vaziri ${ }^{4}$, we needed to remove $1.4 \mathrm{~m}$ from this because of the size of our averaging volume, we arrived at $(11.6-1.4)=10.2 \mathrm{~m}$ or $30.6 \mathrm{ft}$.

With the geometry described above, we calculated the star density per proton for $10^{6}$ 

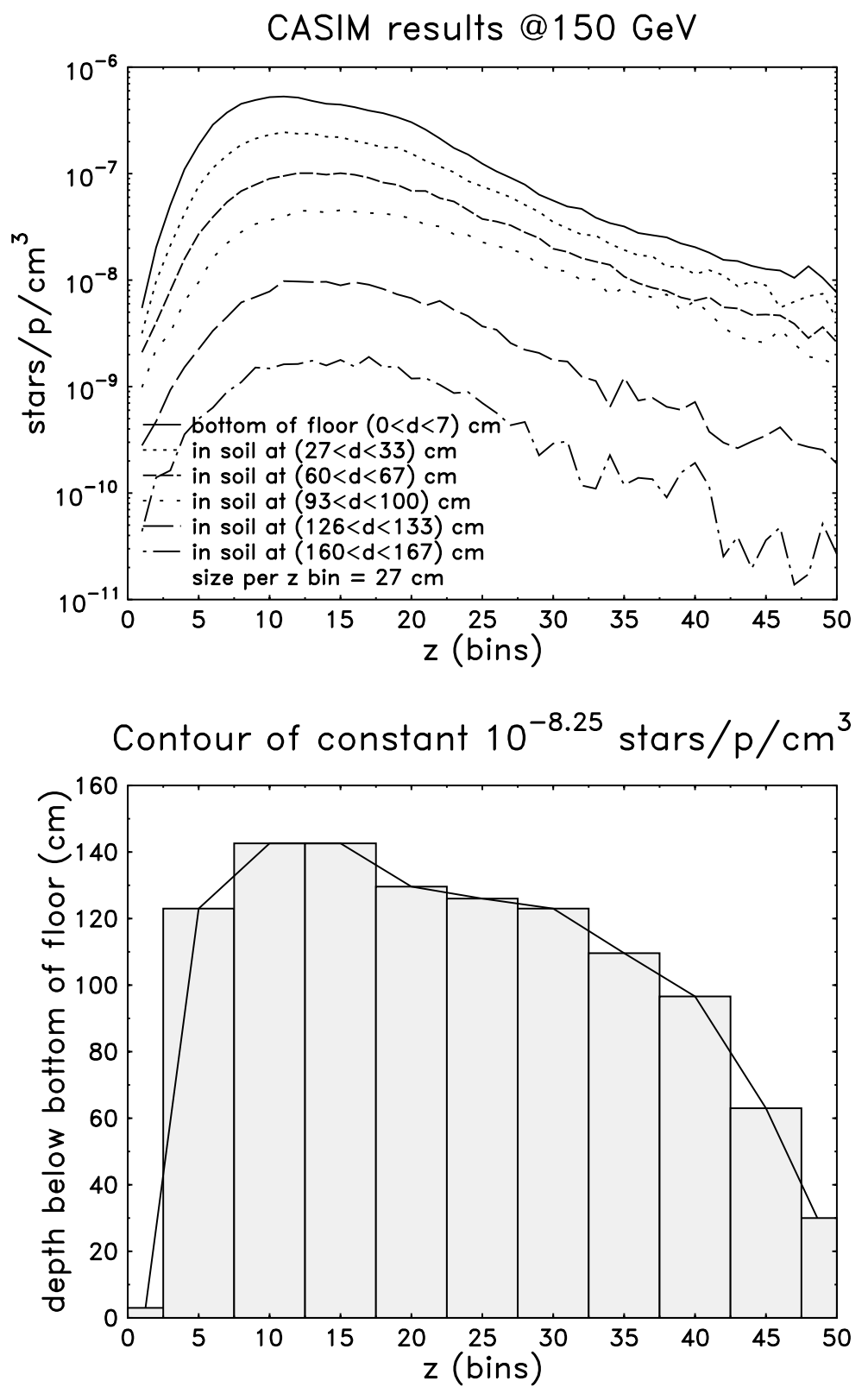

Figure 3 CASIM results at $150 \mathrm{GeV}$ for $\left(\sigma_{x}, \sigma_{y}\right)=(0.15,0.15) \mathrm{cm}^{2}$. The required contour which contains $99 \%$ of the protons in the soil is also shown here with the bin approximations used in CASIM.

incident protons for a incident energies of $150 \mathrm{GeV}$ and $1 \mathrm{TeV}$ for three different transverse 

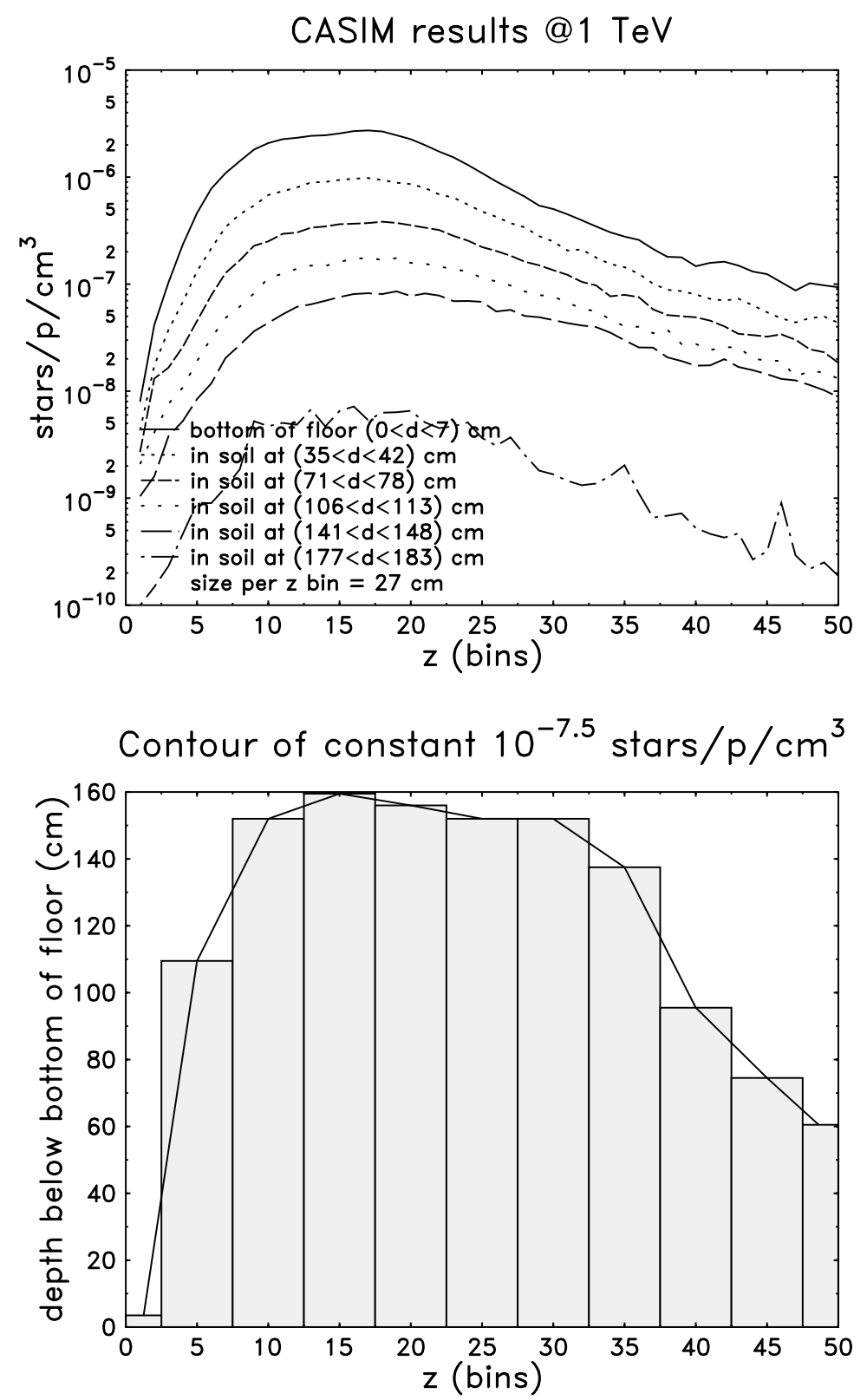

Figure 4 CASIM results at $1 \mathrm{TeV}\left(\sigma_{x}, \sigma_{y}\right)=(0.15,0.15) \mathrm{cm}^{2}$. The required contour which contains $99 \%$ of the protons in the soil is also shown here with the bin approximations used in CASIM.

beam sizes $\left(\sigma_{x}, \sigma_{y}\right):(0.15 \times 0.15) \mathrm{mm}^{2},(0.15 \times 0.15) \mathrm{cm}^{2}$, and $(1.5 \times 1.5) \mathrm{cm}^{2}$. Figures 3 
and 4 for $\left(\sigma_{x}, \sigma_{y}\right)=(0.15,0.15) \mathrm{cm}^{2}$ show how the star density per proton varies as a function of depth into the soil.

In order to calculate the star density per proton $S_{\text {conc }}$ required by the Concentration Model, we identified the peak star density at the top of the soil and then we plotted out the contour which reduced the peak star density per proton by two orders of magnitude. With this contour, we can then calculate the volume occupied by $99 \%$ of the protons and thus arrive at $S_{\text {conc. }}$ For our two cases, when the incident beam is at $150 \mathrm{GeV}$, the peak star density per proton is $10^{-6.25}$ and thus the required contour is $10^{-8.25}$, while for $1 \mathrm{TeV}$, the peak star density per proton is $10^{-5.5}$ and the required contour is $10^{-7.5}$. These two contours are shown in Figures 3, and 4. We then binned these two contours in order to calculate the number of protons in them and by dividing this number with the volume of the bins finally arrive at $S_{\text {conc }}$. The volume of the contour for $150 \mathrm{GeV}$ used in our calculations is $4.0 \times 10^{7} \mathrm{~cm}^{3}$ and for $1 \mathrm{TeV}$ is $4.9 \times 10^{7} \mathrm{~cm}^{3}$.

Table 1 shows the results of the CASIM calculations. The uncertainties in the $S_{\text {conc }}$ column came directly from CASIM and do not take into account the uncertainty in taking the $99 \%$ volume.

\begin{tabular}{l|c|c}
\hline \multicolumn{3}{c}{ Table 1. CASIM results @150 GeV } \\
\hline$\#$ & $\left(\sigma_{x}, \sigma_{y}\right)$ & $S_{\text {conc }}\left(\right.$ stars $\left./ \mathrm{p} / \mathrm{cm}^{3}\right)$ \\
1 & $(0.15,0.15) \mathrm{mm}^{2}$ & $(4.36 \pm 0.04) \times 10^{-8}$ \\
2 & $(0.15,0.15) \mathrm{cm}^{2}$ & $(4.32 \pm 0.04) \times 10^{-8}$ \\
3 & $(1.5,1.5) \mathrm{cm}^{2}$ & $(3.64 \pm 0.02) \times 10^{-8}$ \\
\hline \hline
\end{tabular}




\begin{tabular}{l|c|c}
\hline \multicolumn{3}{c}{ Table 2. CASIM results @1 TeV } \\
\hline$\#$ & $\left(\sigma_{x}, \sigma_{y}\right)$ & $S_{\text {conc }}\left(\right.$ stars $\left./ \mathrm{p} / \mathrm{cm}^{3}\right)$ \\
1 & $(0.15,0.15) \mathrm{mm}^{2}$ & $(1.94 \pm 0.02) \times 10^{-7}$ \\
2 & $(0.15,0.15) \mathrm{cm}^{2}$ & $1.95 \pm 0.03) \times 10^{-7}$ \\
3 & $(1.5,1.5) \mathrm{cm}^{2}$ & $(1.6 \pm 0.02) \times 10^{-7}$ \\
\hline \hline
\end{tabular}




\section{CONCENTRATION MODEL}

With $S_{\text {conc }}$ calculated with CASIM, we then used the Concentration Model to calculate the maximum number of protons that can be aborted at A0. The essential equation used in the Concentration Model is

$$
C_{f}=\frac{N_{p} S_{\text {conc }} K_{i} L_{i}}{1.17 \times 10^{6} \rho_{s} w_{i}} \times R_{\mathrm{till}} R_{\mathrm{mix}} R_{\text {dolomite }}
$$

where

$C_{f}$ is the final concentration of radionuclide $i$ at the aquifer in units of $\mathrm{pCi} / \mathrm{m} \ell /$ year. $N_{p}$ is the number of protons per year.

$S_{\text {conc }}$ is the star density obtained from CASIM in units of stars $/ \mathrm{p} / \mathrm{cm}^{3}$

$K_{i}$ is the probability per star that an atom of the $i$ th nuclide will be produced.

$L_{i}$ is the leaching fraction of the $i$ th nuclide.

$\rho_{s}$ is the density of soil in $\mathrm{g} / \mathrm{cm}^{3}$.

$w_{i}$ is the weight of water divided by the weight of soil that corresponds to $99 \%$ leaching.

$1.17 \times 10^{6}$ converts disintegrations per second into picoCuries (0.037) and years into seconds $\left(3.15 \times 10^{7}\right)$.

$R_{\text {till }}$ is the reduction factor for glacial till.

$R_{\text {mix }}$ is the reduction factor at the interface between the till and the dolomite. $R_{\text {till }}$ is the reduction factor for the dolomite.

The constants that were used in the calculation are given in Table 3. 


\section{Table 3. Constants and Formulæ used in the Concentration Model}

\section{Quantity}

Distance to aquifer, $d(\mathrm{ft})$

Production factor, $K_{i}$

90\% Leachability factor, $L_{i}$

Density, $\rho_{i}\left(\mathrm{~g} / \mathrm{cm}^{3}\right)$

Weight of water for $90 \%$ leaching, $w_{i}$

$$
\begin{gathered}
R_{\text {till }} \\
R_{\text {mix }} \\
R_{\text {dolomite }}
\end{gathered}
$$

Allowed Concentrations (pCi/m $\ell$ )

\begin{tabular}{c|c}
$\mathbf{H}_{3}$ & $\mathbf{N a} 22$ \\
30.6 & 30.6 \\
0.075 & 0.02 \\
0.9 & 0.135 \\
2.25 & 2.25 \\
0.27 & 0.27 \\
$\exp (-0.09144 d)$ & $\exp (-.280416 d)$ \\
1.0 & 1.0 \\
1.0 & 1.0 \\
20 & 0.4 \\
\hline
\end{tabular}

Using the numbers in Table 1,2 and 3 we obtained the maximum number of protons per year that can be aborted in the $\mathrm{A} 0$ abort which would keep $\mathrm{H}_{3}$ and $\mathrm{Na}_{22}$ within legal limits (shown in the last line of Table 3). These results are shown in Table 4 and 5.

\begin{tabular}{l|c|c}
\multicolumn{3}{c}{ Table 4. Maximum Number of Protons Aborted Per Year @150 GeV } \\
\hline$\#$ & Beam size $\left(\sigma_{x}, \sigma_{y}\right)$ & max. protons/year \\
1 & $(0.15,0.15) \mathrm{mm}^{2}$ & $7.6 \times 10^{16}$ \\
2 & $(0.15,0.15) \mathrm{cm}^{2}$ & $7.6 \times 10^{16}$ \\
3 & $(1.5,1.5) \mathrm{cm}^{2}$ & $9.2 \times 10^{16}$ \\
\hline \hline
\end{tabular}

\begin{tabular}{l|c|c}
\hline \multicolumn{2}{c}{ Table 5. Maximum Number of Protons Aborted Per Year @1T TeV } \\
\hline$\#$ & Beam size $\left(\sigma_{x}, \sigma_{y}\right)$ & max. protons/year \\
1 & $(0.15,0.15) \mathrm{mm}^{2}$ & $1.7 \times 10^{16}$ \\
2 & $(0.15,0.15) \mathrm{cm}^{2}$ & $1.7 \times 10^{16}$ \\
3 & $(1.5,1.5) \mathrm{cm}^{2}$ & $2 \times 10^{16}$ \\
\hline \hline
\end{tabular}




\section{CONCLUSION}

From these calculations, we can see that the maximum number of protons that can be aborted in A0 is only weakly dependent on beam size. Thus we conclude that the conservative abort limits are $7.6 \times 10^{16}$ protons per year $@ 150 \mathrm{GeV}$ and $1.7 \times$ $10^{16}$ protons per year @1 TeV.

\section{ACKNOWLEDGEMENTS}

The author wishes to thank M. Girardi, K. Vaziri and G. Koizumi for helping the author understand CASIM and the Concentration Model.

\section{REFERENCES}

[1] Tevatron Collider Internal Beam Abort A0 Abort Dump Assembly, B. Hanna, 1780.090 ME-136361, 1991.

[2] Ground Water Activation Due to the A0 Abort, B. Hanna, 4 Sep. 1991.

[3] Groundwater Migration of Radionuclides at Fermilab, pg. 36, Table 4, A.J. Malensek, A.A. Wehmann, A.J. Elwyn, K.J. Moss and P.M. Kesich, Fermilab-TM-1851, August 1993.

[4] Private Communication, K. Vaziri, 30 Nov 1998. 